\title{
Lifestyle counseling reduces metabolic syndrome prevalence in the short term
}

\section{Consejería estilo de vida reduce la prevalencia de síndrome metabólico en el corto plazo}

\begin{abstract}
The aim of this study was to analyze the effect of lifestyle counseling on metabolic syndrome (MetS) prevalence in the short term. This was a before-after study design conducted in a nutrition outpatient clinic. Participants were adults presenting with MetS according to the International Diabetes Federation criteria. In the study 109 individuals (mean age $41 \pm 9.6$ years old) were included, the majority women (82,6\%). Participants received individualized dietary prescription guidelines for healthy eating and were encouraged to perform physical activity. After five months, a decrease of $21.5 \%$ in the prevalence of MetS $(p<0,001)$ was observed Significant mean reductions $(p<0,001)$ in bodyweight $(3.5 \pm 3.4 \mathrm{Kg})$, waist circumference $(4.0 \pm 4.0 \mathrm{~cm})$, triglycerides $(33.8 \pm 69.6 \mathrm{mg} / \mathrm{dl})$ and fasting glucose we observed $(6.6 \pm 18.3$ $\mathrm{mg} / \mathrm{dl})$, while HDL cholesterol showed an increase $(2.6 \pm 6.1 \mathrm{mg} /$ $d l, p<0,001)$. We conclude that lifestyle counseling consisting of individualized nutritional guidance through a balanced diet, physical activity promotion and change in lifestyle can reduce the prevalence of MetS in the short term.

Key words: Life style; counseling; dietary modification; diet therapy; metabolic syndrome.
\end{abstract}

\section{INTRODUCTION}

Metabolic syndrome (MetS) is defined as a group of interrelated factors of metabolic origin, which contribute directly to cardiovascular disease (CVD) and type 2 Diabetes (DM2). Abdominal obesity, alterations in glucose metabolism, hypertension, altered lipid profile with elevated triglycerides and low levels of high-density lipoprotein cholesterol (HDLC) combined with a pro inflammatory and pro thrombotic state increase the risk of MetS (1-3).

The IDF criteria for MetS are applied according to ethnic group with specific values indicated for south america population. The criteria consist of: 1) central obesity (waist circumference of $90 \mathrm{~cm}$ or greater for men and 80 $\mathrm{cm}$ or greater for women) plus two or more of the following factors: 2) hypertriglyceridemia ( $\geq 150 \mathrm{mg} / \mathrm{dl}$ or use of antilipid medication); 3) low sera levels of HDLc (< $40 \mathrm{mg} / \mathrm{dl}$ for men and $<50 \mathrm{mg} / \mathrm{dl}$ for women, or drug treatment for this condition); 4) systolic arterial blood pressure $\geq 130$ or diastolic pressure $\geq 85 \mathrm{mmHg}$ or use of anti-hypertensive drugs, or; 5) fasting blood glucose level $\geq 100 \mathrm{mg} / \mathrm{ml}$ or previously diagnosed DM2.

The incidence of MetS is increasing and the problem is now considered a public health issue, affecting about $20-25 \%$
Patricia Abrantes Duval $(1,2)$

Denise Halpern-Silveira (3)

Maria Cecilia Formoso Assunção $(1,3)$

(1) Post-graduation Program on Nutrition and Foods, Federal University of Pelotas, Brazil (2) Teaching Hospital of the Federal University of Pelotas, Brazil (3) Department of Nutrition, School of Nutrition, Federal University of Pelotas, Brazil

$$
\begin{array}{r}
\text { Dirigir la correspondencia a: } \\
\text { Profesora } \\
\text { Patricia Abrantes Duval } \\
\text { Teaching Hospital of the Federal University of Pelotas, Brazil } \\
\text { Telefonos: (53) } 32844960 \\
\text { Fax: (53) } 32944929 \\
\text { E-mail: patricia-duval@hotmail.com }
\end{array}
$$

Este trabajo fue recibido el 5 de Marzo de 2013 y aceptado para ser publicado el 8 de Agosto de 2013.

of the adult population worldwide $(1,2,4)$.

The prevalence of MetS in different populations is strongly associated with the criteria used to define it. In 2006, the International Diabetes Federation (IDF) published a new consensus suggesting waist circumference measurements with cutoff points for each population type based on local ethnic characteristics $(4,5)$.

A cohort study conducted in Pelotas located within the state of Rio Grande do Sul, Brazil, during 2004-5 involving 3,599 subjects of both sexes, all aged 22 years old, reported an incidence of $6.7 \%$ for MetS applying IDF criteria (6).

There is a general consensus that each of the MetS components is linked to life-style changes such as sedentary style, imbalance between intake and expend of calories, and high intake of certain types of foods (7).

For these reasons, health measures designed to prevent or control obesity, increase physical activity, promote cessation of smoking and provide education about nutrition for the general population, have been a focus of attention. These practices have resulted in beneficial changes such as weight loss, decrease in plasma glucose levels and arterial blood pressure, as well as lipid profile alterations (8).

The aim of the present study was to analyze the effect 
of lifestyle counseling on metabolic syndrome prevalence in the short term.

\section{SUBJECTS AND METHODS}

Patients and Study Design

This was a effectiveness before-after study conducted at the nutrition outpatient clinic of the UFPel, Brazil. Participants included were both men and women aged between 20 and 59 years old, presenting with MetS according to the IDF criteria, who sought the service voluntarily, between January 2010 and June 2011. The IDF criteria for MetS was chosen for its high sensitivity, using lower cut-off scores than those defined in other criteria for diagnosing MetS (4).

Among the kind of diseases and physiological states common to be referred to the outpatient clinic, patients with cancer, acquired immune deficiency syndrome, or chronic renal disease, and pregnant or lactating mothers, were excluded from this study due to their specific nutritional requirements.

Figure 1 shows the flowchart of the study and the number of participants involved in each phase. Two hundred and fortyfour patients from the Outpatient Clinic of the UFPel Hospital were eligible for the study.

There were three refusals and 50 patients were excluded for non-completion of the preliminary laboratory examinations. After, another 82 patients were excluded for failing to meet the diagnostic criteria for MetS defined by the IDF giving a total of 109 patients for study inclusion.
During the period the study, $60 \%$ of patients completed both sets of laboratory examinations and attended all consultations.

A total of 22 patients (20\%) were lost to follow up for failure to complete the final laboratory exams (T2) or discontinuing the treatment protocol. Twenty-two subjects (20\%) attended follow up sessions but did not perform final laboratory exams. Thus, the 87 patients with body measurements, blood pressure data and physical activity levels available were analyzed, along with the 65 patients with complete laboratory evaluations.

Evaluation of body measurements, clinical history, laboratory findings and behavior

A structured anamnesis entailing clinical and physical examination was used to collect demographic information (sex, age, skin color, marital status and educational level) and anthropometric data (body weight, height and waist circumference).

Weight was measured using a Welmy model 110" balance with a capacity of $150 \mathrm{~kg}$, accurate to the nearest $1 \mathrm{~kg}$, which was recalibrated for each participant.

Height was measured with a metal stadiometer arm of 200 $\mathrm{cm}$, accurate to the nearest $1 \mathrm{~mm}$, fitted to the scale. Weight and height measurements were taken with the patient wearing light clothing and no footwear according to predetermined standard technique (9).

FIGURE 1

Flow chart for study of adult mets patients. Pelotas (RS) 2010-1011.

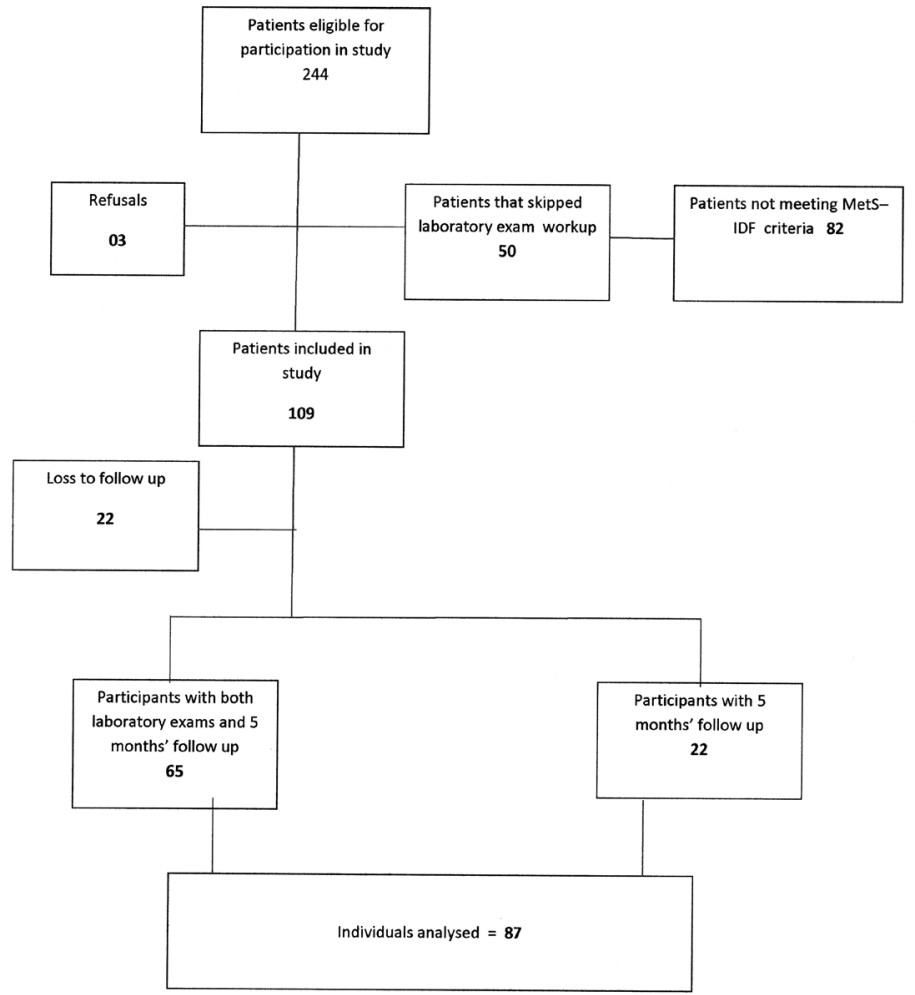


Body Mass Index (BMI) was calculated by dividing weight in $\mathrm{kg}$ by height in meters squared using the cutoffs defined by the World Health Organization. The BMI was categorized as $<18,5 \mathrm{~kg} / \mathrm{m} 2$ labeled as underweight, 18,5 - 24,99 kg/ $\mathrm{m} 2$ normal range, $>25,00 \mathrm{~kg} / \mathrm{m} 2$ overweight, and $>30,00$ $\mathrm{kg} / \mathrm{m} 2$ obesity (10).

Waist measurements were taken using a flexible, nonelastic tape measure of $150 \mathrm{~cm}$ with $0.1 \mathrm{~cm}$ graduations. This measurement was taken at the point of least abdominal curvature (particularly in severely obese individuals) between the anterior superior iliac crest and the last rib, as is standard (9).

Systolic and diastolic blood pressure measurements were taken with a digital pressure cuff for the wrist (Geratherm model KP6130) with the patient at rest for 10 minutes before the measurement was done. The wrist strap was placed around the left wrist, without clothing, and the arm was raised to the level of the heart (11).

Biochemical assays were done by the BioCeleris Laboratory of the UFPel using model Labmax 240 Labtest equipment. The following samples were collected after a 12-hour fast: fasting blood glucose, total cholesterol, triglycerides (TGC), HDLC and low-density lipoprotein cholesterol (LDLC).

Although total cholesterol and LDLc levels are not part of the diagnostic procedure for MetS, they are important indicators of cardiovascular health. normal levels of total cholesterol and LDLc were defined as $<200 \mathrm{mg} / \mathrm{dl}$ and $<100$ $\mathrm{mg} / \mathrm{dl}$, respectively (12).

The International Physical Activity Questionnaire version 6 long form (IPAQ) was used to estimate the time in minutes spent per week on moderate to vigorous physical activities, in different daily contexts. This test defines a sedentary individual as one that performs less than 150 minutes per week of physical activity on the test score. Physical activity at work, during transport, domestic and leisure situations were evaluated. Scores were obtained individually for each category, taking into account the time spent in minutes, and frequency in days per week, on walking and moderate to intense activities. Totals were summed to give the final score (13).

\section{Lifestyle counseling}

The study was explained to the patients at the first meeting and those who agree to participate were asked to sign an Informed Consent. A questionnaire was then performed to collect demographics data and body measurements. The IPAQ was subsequently applied and laboratory tests ordered.

A diet providing $20-25 \mathrm{Kcal} / \mathrm{Kg}$ of current weight per day was prescribed following the recommendations of the First Brazilian Guidelines for the Diagnosis and Treatment of Metabolic Syndrome (14).

The distribution of nutrients in this diet was designed to give $50-60 \%$ of the calories from carbohydrates, $25-35 \%$ from lipids and $15 \%$ from proteins. Consumption of fruits, green leafy vegetables, legumes and whole cereals was encouraged to attain an intake of 20-30 g/day of fiber, as this has beneficial effects on the control of glucose and lipid levels. In order to decrease the total fat content, avoidance of fatty meats, fried foods, whole fat dairy products, coconut oil, cholesterol rich foods, saturated fatty acids and trans fatty acids was recommended. Use of mono saturated oil such as olive oil was suggested to improve lipid profile. Subjects were advised to avoid or moderate salt intake, processed foods such as cold meat, conserved, canned, smoked or salted food products. Season with parsley, spring onions and aromatic herbs was suggested as an alternative to processed condiments and spices (14).
The daily consumption of two to four portions of fruit, at least one of which was to be a citrus fruit rich in Vitamin $C$, as well as three to five portions of raw or cooked vegetables was recommended (14).

A diet sheet divided into three main meals and two or three snacks (food portions amounting to around 100 calories), as well as a list of substitutions, was handed to the patient at the first meeting. Patients were instructed to maintain the nutritional balance of the diet, in which the number of food groups was determined based on the nutritional pyramid recommended for the Brazilian population (15).

In addition to the diet plan, each patient was given a folder containing nutritional information including 10 steps for healthy eating from the Brazilian Dietary Guide (16). Patients were also encouraged to do 30 minutes of moderate aerobic physical exercise most days of the week.

In the case of examinations suggest the presence of hypertension, dyslipidemias and DM2, after dietary advice the patients were referred to the outpatient clinic of the Medical Department of UFPel for further medical follow up.

Five monthly follow-up meetings were scheduled for each patient. Body weight, waist circumference, and blood pressure were measured during each visit. Dietary advice was reiterated, encouragement given to perform physical exercise and any doubts regarding treatment were resolved.

On the fifth and final visit, further laboratory exams were ordered and the IPAQ for physical activity was reapplied. Patients continued to be followed by the service after the study had concluded.

The interviewers for this study (students at the UFPel School of Nutrition) were trained and supervised by the lead nutritionist of the study to ensure the same procedures were adopted for taking anthropometric and blood pressure measurements, and likewise for collecting clinical history and applying the IPAQ.

Ethical considerations

The study was approved by the Research Ethics Committee of the Medical School of UFPel (OF 58/2010). All participants signed an informed consent before entry into the study.

\section{Statistical analysis}

The study sample was determined so as to provide $90 \%$ power with a 5\% significance level to detect minimal differences in MetS components before (Time $1-\mathrm{T} 1$ ) and after (Time 2 -T2).

Study data were entered into Epi-Info ${ }^{\mathrm{TM}} 6.0$ and statistical analyses were performed using Stata ${ }^{T M}$ version 12.0.

Continuous variables were described using mean and standard deviation and for categorical, absolute number and relative frequency were employed.

The paired Student t test was used to analyze different outcomes between intervention baseline and endpoint for variables with a normal distribution such as weight, BMI, waist circumference, blood pressure (systolic and diastolic) and HDLc. Wilcoxon's test was used for variables with asymmetric distribution, such as total cholesterol, LDLC, TGC, and fasting glucose levels.

The Chi squared test was used for categorical values. Pearson's Correlation test was used for continuous variables with a normal distribution (at least one normal variable). All analyses were carried by intention-to-treat and the significance level adopted for all tests was $5 \%$. 


\section{RESULTS}

Table 1 lists the initial characteristics of the 109 participants, such as: age, gender, marital status, educational level, skin color and sedentarism. We observed that the mean age was $41+9.6$ years old, the participants were predominantly female, the majority living with another person, had completed or were completing high-scholl education, considered themselves to be white and were classified as sedentary.

Tables 2 and 3 show the prevalence of MetS and the outcomes of the 65 patients that did laboratory exams at

\section{TABLE 1}

Characteristics of adult MetS patients at study baseline ( $\mathrm{N}=109)$. Pelotas (RS), 2010-2011

\begin{tabular}{lll}
\hline & $N$ & $\%$ \\
Age $\quad$ & \\
Up to 30 years old & 17 & 15.6 \\
$31-40$ years old & 39 & 35.8 \\
$41-50$ years old & 29 & 22.6 \\
$51-59$ years old & 24 & \\
Gender & 19 & 17.4 \\
Male & 90 & 82.6 \\
Female & & \\
Marital status & 69 & 63.3 \\
With companion & 40 & 36.7 \\
Without companion & & \\
Educational level & 41 & 37.6 \\
Primary School & 52 & 47.7 \\
High School & 16 & 14.7 \\
College or greater & & 86.2 \\
Skin color & 94 & 13.8 \\
White & 15 & \\
Non-white & & 64.2 \\
Sedentarism & 70 & 35.8 \\
$\quad$ Yes & 39 & \\
No & & \\
\hline
\end{tabular}

TABLE 2

Prevalence of MetS and altered laboratory results in adults at baseline (T1) and endpoint (T2).

Pelotas, (RS), $20102011(n=65)$

\begin{tabular}{|c|c|c|c|c|c|}
\hline & \multicolumn{2}{|c|}{ T 1} & \multicolumn{2}{|c|}{ T 2} & \multirow[t]{2}{*}{$p$ value $^{*}$} \\
\hline & $\mathrm{N}$ & $\%$ & $\mathrm{~N}$ & $\%$ & \\
\hline \multicolumn{6}{|l|}{ MetS - IDF } \\
\hline Yes & 109 & 100 & 51 & 78.5 & \\
\hline No & 0 & 0 & 14 & 21.5 & \\
\hline Altered HDLc & 56 & 86.2 & 51 & 78.5 & $<0.001$ \\
\hline \multicolumn{6}{|l|}{ men $<40 \mathrm{mg} / \mathrm{dL}$} \\
\hline \multicolumn{6}{|l|}{ women $<50 \mathrm{mg} / \mathrm{dL}$} \\
\hline Triglycerides > $150 \mathrm{mg} / \mathrm{dL}$ & 32 & 49.2 & 25 & 38.5 & $<0.001$ \\
\hline Total Cholesterol >200 mg/dL & 25 & 38.5 & 25 & 38.5 & $<0.001$ \\
\hline LDLc>100 mg/dL & 38 & 58.5 & 42 & 64.6 & $<0.001$ \\
\hline Fasting glucose level > $100 \mathrm{mg} / \mathrm{dL}$ & 35 & 53.9 & 27 & 41.5 & $<0.001$ \\
\hline
\end{tabular}


baseline (T1) and endpoint (T2).

There was a $21.5 \%$ decrease in MetS as defined by the IDF criteria among the 65 patients with complete profiles, 14 of whom no longer met the criteria for MetS at study endpoint.

The biochemical components of MetS (HDLC, TGC and fasting blood glucose) all showed statistically significant alterations $(p<0.001)$ between study baseline and endpoint.

Body measurements, pressure arterial and physical activity of the total 87 patients were evaluated at baseline (T1) and endpoint (T2) are show in tables 4 and 5 . This number includes 22 patients who did not undergo laboratory final tests but have the measures described above.

A significant positive effect of the study $(p<0.001)$ was observed for weight, BMI and waist circumference.

Difference in diastolic arterial pressure was also significant $(p=0.02)$ at follow up. By contrast, no change in systolic blood pressure, total cholesterol or LDLc was evident between T1 and $\mathrm{T} 2$.

From T1 to T2, a mean increase of the minutes in physical activity per week $(p=0.002)$ and in physical leisure activity, was found over the study period $(p<0,001)$.

In addition, a significant alteration $(p<0.001)$ was also seen in the distribution of $\mathrm{BMI}$ with a $15 \%$ decrease in the number of obese patients (13 patients) and a consequent $14 \%$ increase in patients classified as overweight (12 patients). One patient was reclassified into the normal weight range at study endpoint.

Neither systolic nor diastolic measurements showed significant differences according to the IDF criteria at the end of the study.

A $6.9 \%$ decrease in the prevalence of sedentary behavior occurred during the study period ( $p<0.001)$.

A total of 28 individuals (32\%) had a $5 \%$ or greater weight loss during the study but no significant association was found between this loss and any of the outcomes studied.

\section{DISCUSSION}

This study, carried out at the Nutritional Outpatient Clinic of the UFPel Hospital with MetS patients selected according to IDF criteria, showed a decrease in the prevalence of MetS

\section{TABLE 3}

Results in laboratory exams at baseline (T1) and endpoint (T2) in adult MetS patients. Pelotas (RS), 2010-2011 (N=65

\begin{tabular}{|c|c|c|c|c|c|}
\hline & \multicolumn{2}{|c|}{$\mathrm{T} 1$} & \multicolumn{2}{|c|}{$\mathrm{T} 2$} & \multirow[t]{2}{*}{$p$ value ${ }^{*}$} \\
\hline & $M$ & SD & $M$ & SD & \\
\hline Total Cholesterol (mg/dL) & 190.0 & 39.3 & 189.6 & 32.9 & 0.66 \\
\hline HDLc (mg/dL) & 41.9 & 8.8 & 44.5 & 8.8 & $<0.001$ \\
\hline LDLc (mg/dL) & 112.5 & 34.0 & 115.8 & 29.3 & 0.09 \\
\hline Triglycrides (mg/dL) & 177.4 & 104.1 & 143.6 & 65.3 & $<0.001$ \\
\hline Fasting glucose (mg/dL) & 107.6 & 33.1 & 101.0 & 23.3 & $<0.001$ \\
\hline
\end{tabular}

Values expresses as mean $(M)$ and standard deviation (SD)

* Wilcoxon Test

\section{TABLE 4}

Anthropometry, arterial pressure and behavioral changes between baseline (T1) and endpoint (T2) in adult MetS patients $(\mathrm{N}=87)$

\begin{tabular}{|c|c|c|c|c|c|}
\hline & \multicolumn{2}{|c|}{ T1 } & \multicolumn{2}{|c|}{$\mathrm{T} 2$} & \multirow[t]{2}{*}{$\mathrm{p}$ value } \\
\hline & $M$ & SD & $M$ & SD & \\
\hline Weight (Kg) & 87.8 & 16.5 & 84.3 & 16.2 & $<0.001^{*}$ \\
\hline $\mathrm{BMI}\left(\mathrm{Kg} / \mathrm{m}^{2}\right)$ & 33.8 & 5.0 & 32.4 & 4.8 & $<0.001^{*}$ \\
\hline Waist circumference $(\mathrm{cm})$ & 103.4 & 12.8 & 99.4 & 12.0 & $<0.001^{*}$ \\
\hline Systolic arterial pressure (mmHg) & 135.2 & 15.8 & 132.6 & 14.4 & $0.14^{*}$ \\
\hline Diastolic arterial pressure $(\mathrm{mmHg})$ & 89.6 & 11.6 & 86.0 & 9.9 & $0.02^{*}$ \\
\hline \multicolumn{6}{|l|}{ Physical activity (minutes/week) } \\
\hline Total score & 188.6 & 328.0 & 268.7 & 385.0 & $<0.002^{* *}$ \\
\hline Physical Activity (leisure time) & 47.9 & 145.4 & 116.7 & 229.1 & $<0.001^{* *}$ \\
\hline
\end{tabular}


as well as significant alterations in body measurements, laboratory exam results and behavior, as evidenced by comparing initial with final results.

Overall, the prevalence of MetS/IDF decreased by $21.5 \%$. However, as 22 patients did not complete their final round of laboratory exams, it was not possible to confirm any changes in their respective diagnosis of MetS.

Muzio et al (17) ran a randomized clinical trial spanning five months in 100 obese patients at the Ambulatory Care Clinic of the G.Salvini Hospital in Milan, Italy, using the NCEPATPIII diagnostic criteria (MetS/NCEPATPIII). These authors reported a greater reduction in the prevalence of MetS of $54 \%$ in the group which followed a low glucose diet, and of $40 \%$ in the group with a high glucose content diet. The cited study excluded patients with DM2 and thyroid diseases. It should also be noted that the body measurements and lipid profiles of these patients were greater than those of patients in the present study.

Hermsdorff et al (18) found similar results in body measurements, again using a before and after study design in an intervention, with a sample size of 41 obese patients of both sexes. This group reported an average weight loss of $4.4 \mathrm{Kg}$, a $\mathrm{BMI}$ decrease of $1.9 \mathrm{Kg} / \mathrm{m} 2$ and a waist circumference decrease of $5.9 \mathrm{~cm}$. For the study, a hypo caloric diet was used for two months. Habitual physical activity levels were maintained and no specific exercise program was given.

In relation to blood pressure, a randomized, controlled study conducted at an ambulatory care clinic of a Greek University Hospital in 107 overweight or obese women diagnosed with MetS/NCEP-ATPIII, found a reduction of $6.5 \% \mathrm{~mm} \mathrm{Hg}$, greater than we found. The study used a hypo caloric diet, and excluded patients with DM2, thyroid disease, as well as those with ischemic vascular and endocrine diseases (19). Franklin (20), in one of the Framingham studies publications, showed that a reduction in diastolic blood pressure was a positive outcome, as this is considered a more important risk factor for cardiovascular disease than systolic pressure in individuals younger than 50 years old, the same age group as the patients investigated in the our study (mean 41 years).

In the present study, an improvement in glucose, HDLc and TGC levels was observed. This finding was similar to the result found by a randomized controlled study performed in South Korea involving 32 women with MetS/NCEP-ATP III, who had a significant increase in HDLc of $6.5 \mathrm{mg} / \mathrm{dl}$, a decrease in triglyceride levels of $52.2 \mathrm{mg} / \mathrm{dl}$ and a decrease in glucose levels of $13.4 \mathrm{mg} / \mathrm{dl}$. The study lasted one month, and consisted of a hypo caloric diet, as well as supervised exercises of one hour, three times a week, plus health guidance (21). The report suggested that the alterations in lipid profile as well as fasting glucose levels stemmed from the beneficial effects of physical exercise, with an improvement in glucose control and insulin sensitivity, weight loss and decrease in abdominal fat (22).

In terms of physical activity, similar alterations to those seen in our study were found in a randomized controlled study of 241 overweight and/or obese individuals of both sexes from Pelotas, Brazil, during the six-month. This group was given a diet and to practice physical exercise. The intervention group was found to have a significant increase of 88 minute of physical activity per week during leisure time (23). These findings closely resembled those of the present study, perhaps because both studies took place in the same nutrition outpatient clinic, and thus the sample populations were probably similar.

In the present study, 32\% the patients had a weight loss greater than or equal to $5 \%$ during the follow up period, greater than the loss reported by Barbato (24). In the 4-month study of 100 obese patients, $21 \%$ lost $5 \%$ or more of their body weight by end of the follow up.

Participants in our study all voluntarily asked to be seen at the nutritional outpatient clinic, and all attended return visits and went for laboratory examinations without prompting. In this regard, our study can also be considered a study of effectivity, reflecting conditions encountered during routine clinical practice (25).

Loss to follow up due to non-attendance of return visits and noncompliance with laboratory exams at the end of the study, although scheduled with a month advance notice, similar to regular clinical service, may have been due to forgetfulness. Lack of dietary compliance may be related to emotional factors, such as depression and chronic stress, as both are known to influence patient adherence to life-style changes, consequently affecting the study results (26).

Similar studies also report follow up losses. A study conducted in Canada by Meckling (27) in 44 obese or overweight women, found a $27 \%$ loss to follow up. The author considered this to be due to the fact that some participants were not randomized for the exercise program and to the lengthy study

\section{TABLE 5}

BMI classification, arterial pressure and sedentarism in adults baseline (T1) and endpoint (T2). ( $N=87)$

\begin{tabular}{|c|c|c|c|c|c|}
\hline & \multicolumn{2}{|c|}{$\mathrm{T} 1$} & \multicolumn{2}{|c|}{ T 2} & \multirow[t]{2}{*}{$p$ value $e^{*}$} \\
\hline & $\mathrm{n}$ & $\%$ & $\mathrm{n}$ & $\%$ & \\
\hline $\mathrm{BMI}\left(\mathrm{Kg} / \mathrm{m}^{2}\right)$ & & & & & $<0.001$ \\
\hline Adequate weight & 01 & 1.2 & 02 & 2.3 & \\
\hline Overweight & 20 & 23.0 & 32 & 36.8 & \\
\hline Obese & 66 & 75.9 & 53 & 60.9 & \\
\hline Systolic arterial pressure $>130 \mathrm{mmHg}$ & 56 & 64.4 & 47 & 54.0 & 0.07 \\
\hline Diastolic arterial pressure $>85 \mathrm{mmHg}$ & 62 & 71.3 & 44 & 50.6 & 0.155 \\
\hline Sedentarism & 55 & 63.2 & 49 & 56.3 & $<0.001$ \\
\hline
\end{tabular}


time. In a four month intervention study performed in Rio de Janeiro, Brazil, of 100 obese individuals, 13\% were lost to follow up due to voluntary withdrawal, concurrent clinical problems and pregnancy (24).

The lack of a control group is the major limitation of this study. However, significant changes were observed between the variables of MetS diagnostic. Another limitation was the lack of a structured physical activity program with the participation of trained professionals. In spite of this, a significant decline in sedentary behaviour was observed during the study based solely on encouragement given by the staff team.

The lack of any association between total cholesterol levels, LDLc concentration and systolic blood pressure could have been due to the short follow up time, the lack of dietary physical activity compliance. With respect to systolic blood pressure, the number of participants fell below the level deemed necessary for study sample size, and lacked statistical power for analysis.

Studies have shown that life-style interventions, emphasizing an adequate diet and regular physical activity, are the first choice of therapy for MetS. These programs favor a reduction in body weight, waist circumference and abdominal fat. They also improve insulin sensitivity, decrease plasma glucose and triglyceride levels, increase the HDLc levels and consequently reduce risk factors associated with CVD and DM2. As such, modifying life style contributes to better control of MetS by preventing its complications and improving quality of life $(22,29-32)$

A balanced diet rich in fruits and vegetables, foods which are good sources of fibers, whole grains, low saturated fats, trans isomeric fatty acids, simple sugars as well as foods with low sodium content, all contribute to better control of the MetS. These foods are considered indispensable factors for the prevention of the complications associated to MetS $(3,15,33)$.

\section{CONCLUSION}

The results of the present study can show that lifestyle counseling comprising individualized nutritional modifications via a balance diet, encouragement to practice more physical exercise, and a consequent change in life style, are able to prevent or lower the prevalence of risk factors for MetS and CVD within a relatively brief period of time.

\section{RESUMEN}

El objetivo de este estudio fue analizar el efecto de instrucciones relacionadas al estilo de vida sobre la prevalencia de síndrome metabólico (SM) a corto plazo. Este fue un estudio tipo estudio de antes y después realizado en un ambulatorio de nutrición. Los participantes eran adultos que presentan SM según los criterios de la International Diabetes Federation. El estudio incluyó 109 personas (edad media $41 \pm 9,6$ años), en su mayoría mujeres $(82,6 \%)$. Los participantes recibieron una dieta con prescripción individualizada, pautas de alimentación saludable, y se les motivó a practicar actividad física. Después de cinco meses se observó una disminución de 21,5\% en la prevalencia de $S M(P<0,001)$. Se observó una reducción media significativa $(p<0,001)$ en el peso corporal $(3.5+3.4 \mathrm{Kg})$, circunferencia de cintura $(4.0+4.0 \mathrm{~cm})$, triglicéridos $(33.8+$ $69.6 \mathrm{mg} / \mathrm{dl})$ y glucosa en ayunas $(6.6+18.3 \mathrm{mg} / \mathrm{dl})$, mientras que mostró un aumento de HDLc $(2.6+6.1 \mathrm{mg} / \mathrm{dl})(\mathrm{p}<0,001)$. Consejos relacionados al estilo de vida através de una guía de nutrición individualizada dieta equilibrada, la promoción de actividad física y cambios en el estilo de vida pueden reducir la prevalencia de SM a corto plazo.
Palabras clave: estilo de vida; consejos; modificación dietética; dietoterapia; síndrome metabólico.

\section{BIBLIOGRAFÍA}

1. Alberti $K G$, Eckel RH, Grundy SM, et al. Harmonizing the metabolic syndrome: a joint interim statement of the International Diabetes Federation Task Force on Epidemiology and Prevention; National Heart, Lung, and Blood Institute; American Heart Association; World Heart Federation; International Atherosclerosis Society; and International Association for the Study of Obesity. Circulation. 2009 20;120(16):1640-5.

2. Penalva D. Síndrome Metabólica: diagnóstico e tratamento. Rev Med (São Paulo). 2008;87(4):245-50.

3. Zhang SX, Guo HW, Wan WT, Xue K. Nutrition education guided by Dietary Guidelines for Chinese Residents on metabolic syndrome characteristics, adipokines and inflammatory markers. Asia Pac J Clin Nutr. 2011;20(1):77-86.

4. Federation ID. The IDF consensus worldwide definition of the Metabolic Syndrome. Belgium; 2006.

5. Picon PX ZC, Gerchman F, Zelmanovitz T, Gross JL, Canani $L H$. Análise dos critérios de definição da Síndrome Metabólica em pacientes com Diabetes Melito Tipo 2. Arq Bras Endocrinol Metabol. 2006;50(2):264-70.

6. Silveira VM, Horta $B L$, Gigante $D P$, Azevedo Junior $M R$. Metabolic syndrome in the 1982 Pelotas cohort: effect of contemporary lifestyle and socioeconomic status. Arq Bras Endocrinol Metabol. 2010 Jun;54(4):390-7.

7. Martín PM PE, Pascual ALC. Nutrición y Síndrome Metabólico. Rev Esp Salud Pública. 2007;81:489-505.

8. Rezende FAC RL, Ribeiro, RCL, Vidigal, FC, Vasques, $A C J$, Bonard IS. Índice de massa Corporal e Circunferência Abdominal: Associação de Fatores de Risco Cardiovascular. Arq Bras Cardiol. 2006;87(6):728-34.

9. Kac G SR, Gigante DP. Epidemiologia Nutricional. São Paulo: Editora Fiocruz, Editora Atheneu; 2007.

10. Organization WH. Physical Status: The Use and Interpetation of Anthropometry. Report of a WHO Expert Commitee. Technical Report Series. Geneva; 1995.

11. Geratherm. Medical Diagnostic Systems. Blood Pressure Pass Accessed. http:/www.geratherm.com,.br/site, 2010.

12. Program NCE. Detection, Evaluation, and Treatment oh High Blood Cholesterol in Adults (Adult Treatment Panel III). Final Report: NIH Publication; 2002.

13. Questionaire IPA. Guidelines for Data Processing and Analysis of the International Physical Activity Questionaire (IPAQ) - Short and Long Forms IPAQ Research Commitee; 2005.

14. Cardiologia SBd. I Diretriz Brasileira de Diagnóstico e Tratamento da Síndrome Metabólica. Arq Bras Cardiol. 2005;84(1):1-28.

15. Philippi ST LA, Cruz ATR, Ribeiro LC. Pirâmide Alimentar Adaptada: Guia para escolha dos alimentos. Rev Nutr 1999;12(1):65-80.

16. Ministério da Saúde. Guia Alimentar para a População Brasileira. Promovendo a Alimentação Saudável. Série A Normas e Manuais Técnicos.: MS; 2006.

17. Muzio F, Mondazzi L, Harris WS, Sommariva D, Branchi A. Effects of moderate variations in the macronutrient content of the diet on cardiovascular disease risk factors in obese patients with the metabolic syndrome. Am J Clin Nutr. 2007 ;86(4):946-51.

18. Hermsdorff HH, Zulet MA, Abete I, JA. M. Discriminated benefits of a Mediterranean dietary pattern within a 
hypocaloric diet program on plasma RBP4 concentrations and other inflammatory markers in obese subjects. Endocr. $2009 ; 36(3): 445-51$.

19. Evangelou P TT, Christou G, Elisaf MS, Kiortsis DN. Does the Presence of Metabolic Syndrome Influence Weight Loss in Obese and Overweight Women? . Metab Syndr Relat Disord. 2010;8(2):173-8.

20. Franklin SS LM, Khan SA, Wong ND, Leip EP, Kannel WB, et al. . Does the Relation of Blood Pressure to Coronary Heart Disease Risk Change With Aging? : The Framingham Heart Study. Circulation. 2001;103:1245-49.

21. Oh EG, Hyun SS, Kim SH, et al. A randomized controlled trial of therapeutic lifestyle modification in rural women with metabolic syndrome: a pilot study. Metabolism. 2008 Feb;57(2):255-61.

22. Jiamsripong $P$, Mookadam M, Alharthi MS, Khandheria BK, F. M. The metabolic syndrome and cardiovascular disease: part 2. Prev Cardiol. 2008 Fall;11(4):223-9.

23. Assuncao MC, Gigante DP, Cardoso MA, Sartorelli DS, IS. S. Randomized, controlled trial promotes physical activity and reduces consumption of sweets and sodium among overweight and obese adults. Nutr Res. 2010 Aug;30(8):541-9.

24. Barbato $K B G M R$, Rodrigues $M L G$, Braga JUB, Francischetti EA, Genelhu V. Efeitos da Redução de Peso Superior a 5\% nos Perfis Hemodinâmico, Metabólico e Neuroendócrino de Obesos Grau I. Arq Bras Cardiol. 2006;87(1):12-21.

25. Medronho R, Bloch KV, Luiz RR, Werneck GL. Epidemio- logia. São Paulo: Editora Atheneu; 2010.

26. Sharovsky LL ÁA, Perez GH, Romano BW. Tratamento não farmacológico da síndrome metabólica: visão do psicólogo e do nutricionista. Rev Bras Hipertens. 2005;12(3):182-5.

27. Meckling KA SR. A randomized trial of a hypocaloric high-protein diet, with and without exercise, on weight loss, fitness, and markers oh the Metabolic Syndrome in overweight and obese women. Appl Physiol Nutr Metab 2007;32:743-52.

28. Soca $P$. El síndrome metabólico: um alto riesgo para indivíduos sedentários. Acimed. 2009;20(1):1-7.

29. Magkos F, Yannakoulia M, JL C, CS. M. Management of the metabolic syndrome and type 2 diabetes through lifestyle modification. Ann Rev Nutr. 2009;29:223-56.

30. McLellan KCP BS, Cattalini M, Lerario AC. Diabetes mellitus do tipo 2, síndrome metabólica e modificação no estilo de vida. Rev Nutr Campinas. 2007;20(5):515-24.

31. Jaramillo P. Tratamiento de la hipertensión arterial em el paciente com síndrome metabólico. Rev Colomb Cardiol. 2010;17:22-7.

32. Brown T, Avenell A, Edmunds LD, et al. Systematic review of long-term lifestyle interventions to prevent weight gain and morbidity in adults. Obes Rev. 2009 Nov;10(6):62738.

33. Steemburgo T DAV, Gross JL, Azevedo MJ. Fatores Dietéticos e Síndrome Metabólica. Arq Bras Endocrinol Metab. 2007;51(9):1425-33. 